\title{
Our own method of fixation of biodegradable tracheal stent
}

\author{
Hytych $\mathrm{V}^{1}$, Horazdovsky $\mathrm{P}^{1}$, Stehlik $\mathrm{L}^{2}$, Pracharova $\mathrm{S}^{1}$, Pohnan $\mathrm{R}^{1,3}$, Lefnerova $\mathrm{S}^{2}$, Vasakova $\mathrm{M}^{2}$
}

Department of Thoracic Surgery of Thomayer's Hospital, Prague, Czech Republic. Vladislav.hytych@ftn.cz

\begin{abstract}
The authors present their own unique original method of fixation polydioxan biodegradable stents in the treatment of tracheal stenosis documented by pictures and video (Fig. 3, Ref. 12). Text in PDF www.elis.sk. Key words: tracheal stenosis, stent, biodegradable stent, fixation of biodegradable stent.
\end{abstract}

\section{Tracheal stenosis}

The trachea connects the larynx and bronchi, this tube is 10-12 $\mathrm{cm}$ long, cranially it builds on cricoid cartilage and caudally it ends with bifurcation. The wall is reinforced with 16-20 horseshoe-shaped cartilages that prevent collapse of the lumen. There is pars membranacea between the ends of the cartilages, which forms the back wall of the trachea. According to the anatomy we divide the trachea into the pars cervicalis located in the front part of the neck area and the pars thoracica, which is located in the upper mediastinum (1).

Tracheal stenosis can be divided into congenital and acquired, benign and malignant, and idiopathic.

Congenital stenosis is one of the very rare anomalies from agenesis and aplasia, through segmental or diffuse narrowing, tracheoesophageal fistula, congenital tracheomalacia to extramural oppression of large vessels (innominate artery syndrome, double aortic arch, aberrant left pulmonary artery). Congenital stenosis of the trachea has historically poor prognosis with mortality about $50 \%(2)$.

Idiopathic subglottic stenosis affects almost exclusively women. One group responds well to laser therapy and dilatation and in the second group it leads to formation of a solid scar tissue which needs to be solved by resection and reconstruction (3). Part of etiology is attributed to gastroesophageal reflux (4).

Malignant stenoses are caused by primary or secondary tumors or by penetration of tumors from the surroundings. The most common primary tumors are adenoid cystic carcinoma (40\%), epidermoid carcinoma (36\%) and neuroendocrine carcinoma. Malignant melanoma, lung cancer or lymphoma can form the

${ }^{1}$ Department of Thoracic Surgery of Thomayer's Hospital, Prague, Czech Republic, ${ }^{2}$ Department of Respiratory Medicine of The First Faculty of Medicine of the Charles University and Thomayer's Hospital, Prague, Czech Republic, and ${ }^{3}$ Surgical Clinic of The Second Faculty of Medicine of the Charles University and the Military University Hospital, Prague, Czech Republic

Address for correspondence: V. Hytych, MD, PhD, Department of Thoracic Surgery, Thomayer's Hospital, Videnska 800, CZ-140 59 Prague 4 - Krc, Czech Republic.

Phone: +420.734767704 metastases. From the surroundings carcinoma of the larynx, lung cancer, esophageal cancer or thyroid cancer can grow through the trachea.

Benign stenoses include nonmalignant constriction of the trachea together with benign tumors. The vast majority is represented by stenoses after intubation and after tracheostomy as well posttraumatic and after resection. In addition fungal infections, tuberculosis, sarcoidosis, Wegener's granulomatosis or rheumatoid arthritis can be the cause. Benign tumors are found primarily in children and adolescent patients. The most common benign tumors are papillomas, fibromas and haemangiomas (5).

The diagnosis is based on bronchoscopy, 3D computed tomography (virtual bronchoscopy) and magnetic resonance (6).

The method of choice in the treatment of tracheal stenoses is a resection of the trachea from cervical approach or from the right posterolateral thoracotomy (7).

In patients, who for any reason are contraindicated for surgical treatment, the bronchological intervention therapy comes into play. The main indications are dyspnoea, haemorrhage and poststenotic pneumonia (8).

This treatment involves primarily a dilatation with balloon catheter, laser-assisted excision and division, electrocautery, argon - plasma coagulation, cryotherapy, chemical and radiological therapy (brachytherapy), and especially an insertion of the stent.

At the end of the nineteenth century British dentist Charles R. Stent developed a material for teeth impressions, which later began to be used for production of the matrix for the preparation of skin grafts. Since then, the term STENT is used for devices that allow you to maintain patency of the organs and tissues of the tubular character.

Currently used stents are silicone (Montgomer's T tube, Dumon with thorns preventing migration and self-expanding and dilatating Polyflex), hybrid (Freitag-Dynamic stent, Novastent) and a metallic self-expanding (Ultraflex Palmaz and Wallstent) (9).

Silicone stents are currently commonly used in benign stenoses where we assume their removal. Metallic stents are used in malignant stenoses (10).

The most frequent complications after insertion of the stent are an overgrowth of granulation at its ends (8-17\%), a migration and a dislocation (almost $20 \%$ ) (11). 


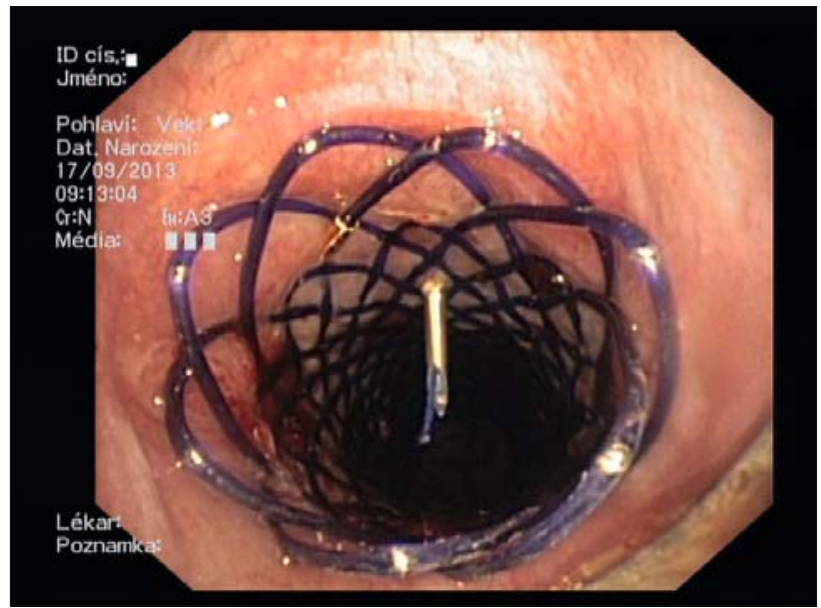

Fig. 1. Monofilament fiber threated through cannula.

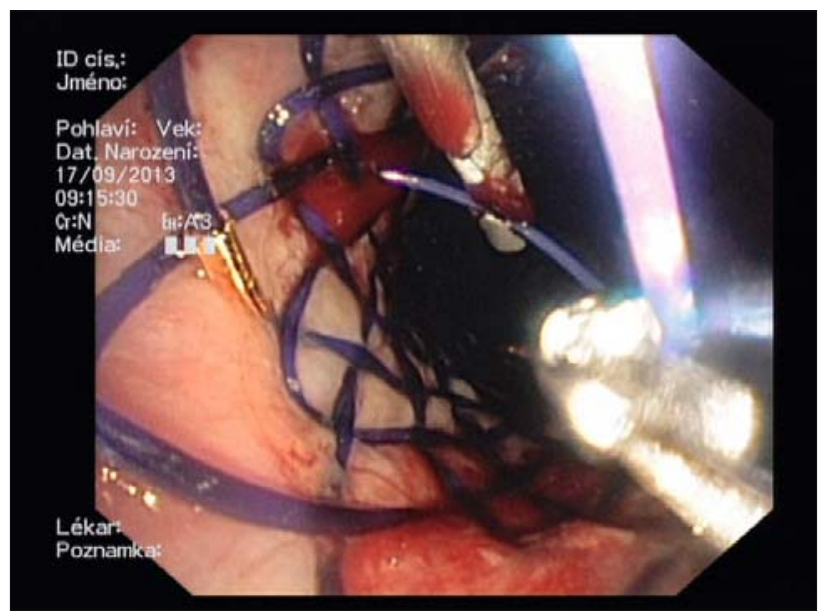

Fig. 2. Fiber catched by endoscopic forceps.

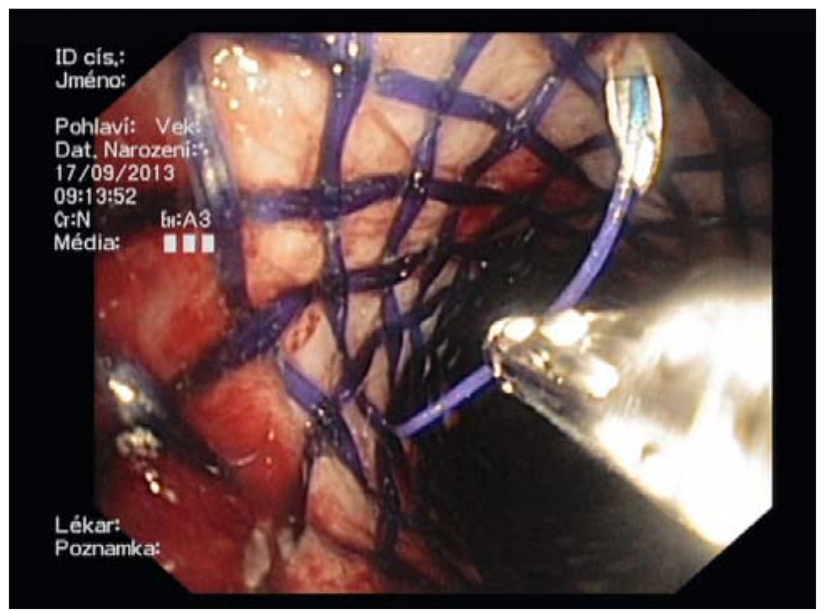

Fig. 3. Fibre catched by atraumatic percutaneous hook.

\section{The research project}

This is a prospective non-randomized interventional study investigating the applicability and effectiveness of polydioxan

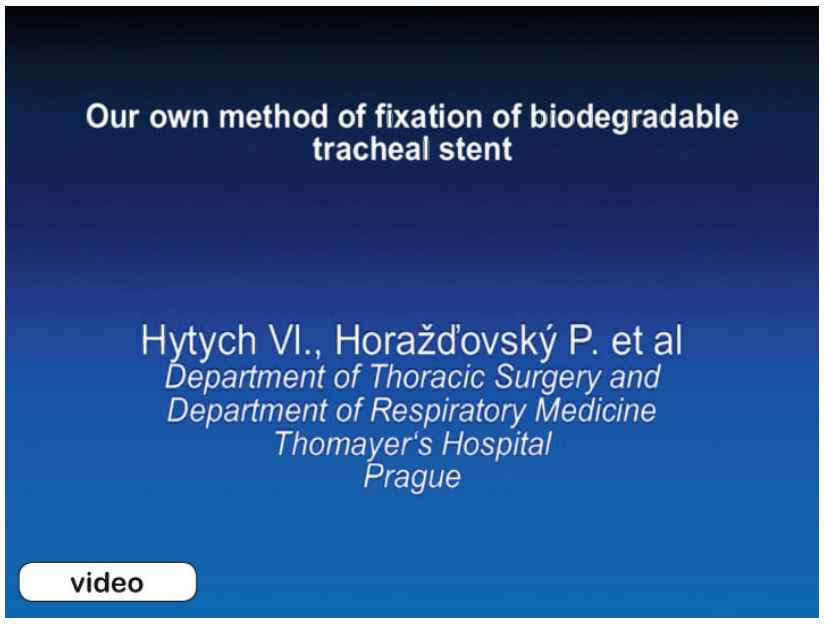

biodegradable stents in the treatment of stenosis of the trachea and main bronchi. It builds on the results of polydioxan stents used in the past for mechanical support of various hollow organs, including the respiratory tract. Indicating criteria for the use of biodegradable stents in the trachea and main bronchi are in contrast to previous studies wider - this is a functionally significant stenosis of benign as well as malignant etiology in case of existence of indication of treatment with stent.

The study includes regular monitoring of patients with established stent, analysis of clinical and functional effect, analysis of the development of the endoscopic image, analysis of potential side effects, statistical evaluation of the results and their publication.

It is expected to confirm the effectiveness of stents and introduction of the method into clinical practice in the future (12).

\section{Our own method of fixation of biodegradable tracheal stent}

After the insertion of biodegradable stent, its exact location and dilatation, its own percutaneous fixation is followed.

We inserted a videobroncoscope through the trachea and we measured using endoscopic forceps the distance from the lower edge of the thyroid cartilage, where distal input will be placed on the skin.

On the skin of the neck in the midline of the trachea at a suitable distance from the lower edge of the thyroid cartilage we mark the place where we insert metal cannula perpendicular to the wall of the trachea under endotracheal control. We thread through this cannula into the lumen of the trachea a fiber (Fig. 1) that we catched using the endoscopic forceps, and we tightened it (Fig. 2). Than we inserted approximately $1.5 \mathrm{~cm}$ cranially above the metal cannula an atraumatic percutaneous hook, for example Endo Close, by which we catched strained fiber (Fig. 3) and we pulled out through a puncture through the skin of the neck. In the trachea we released the end of the fiber with endoscopic forceps.

We fastened the fiber with bundles via padded silicone drain $\mathrm{Ch}$ 4 which creates a flexible traction and prevents the release of fiber.

We removed the fixing stitch after 2-3 weeks, when the stent was already fixed with a pressure into the surrounding tissue. 
340-342

\section{Conclusion}

Polydioxan biodegradable stents are new quality in the treatment of stenosis of the trachea and main bronchi. They build on the results and experiences of the stents used in the past for mechanical support of other hollow organs and tissues.

Fixation of stents prevents their displacement and migration and it allows calmness and time for natural healing into the wall of the trachea.

\section{References}

1. Nagy D. Chirurgische anatomie thorax. Akadémiai Kiadó, 1962.

2. Braman SS, Gaissert HA. Upper Airway Obstruction. In: Fishman AP et al. Pulmonary Diseases and Disorders. The McGraw-Hill Companies, Inc. 1998.

3. Benjamin B, Jacobson I, Eckstein R. Idiopathic subglottic stenosis: Diagnosis and endoscopic laser treatment. Ann Otol Rhinol Laryngol 1997; 106: 770-774.

4. Maronian NC, Azadeh H, Waugh P et al. Association of laryngeal stenosis-oesophageal reflux disease and subglottic stenosis. Ann Otol Rhinol Laryngol 606; 2001: 606-611.
5. Volcheck GW, Dellen RG. Dyspnea with "wheezing" in a 75-year-old female. Ann Allergy Asthma Immunol 1998; 81; 309-314.

6. Triglia JM, Sudre-Levillain I, Marcino S et al. Virtual laryngotracheal endoscopy based on geometric surface modeling using spiral computed tomography data. Ann Otol Rhinol Laryngol 2002; 111: 36-43.

7. Hytych V. Operace plic. In: Hytych V et al. Minimum z plicní chirurgie. Praha: Maxdorf, 2013.

8. Bollinger CH, Mathur PN et al. ERS/ATS statement on interventional pulmonology. Eur Respir J 2002: 19: 356-373.

9. Hert F, Becker HD et al. Succesful Bronchoscopic Placement of Tracheobronchial Stents without Fluoroscopy. Chest 2001; 119: 1910-1912.

10. Papai $Z$ et al. Tracheobronchial stenting of malignant and benign obstruction of large airways. Chest 2003; 124 (Suppl 4): 124.

11. Vergnon JM et al.: Efficacy and tolerance of a new silicone stent for treatment of benign tracheal stenosis. Chest 2000; 118: 422-426.

12. Biodegradabilní stenty v řešení stenóz velkých dýchacích cest. Výzkumný projekt NT 14146-3/ 2013 MZ ČR.

Received May 23, 2014.

Accepted June 30, 2014. 